\title{
Initiation interne de la traduction et stress cellulaire : des infections virales au choc thermique
}

\section{RÉFÉRENCES}

1. Kozak M. Point mutations define a sequence flanking the AUG initiator codon that modulatcs translation by eukaryotic ribosomes. Cell 1986 ; 44 : 283-92.

2. Kozak M. Bifunctional messenger RNAs in eukaryotes. Cell $1986 ; 47: 481-3$.

3. Herman RC. Alternatives for the initiation of translation. Trends Biochern Sci 1989; 14 : 219-22.

4. Jackson RJ, Howell MT, Kaminski A. The novel mechanism of initiation of picornavirus RNA translation. Trends Biochem $\mathrm{Sci}$ $1990 ; 15: 477-483$.

5. Dolph PJ, Racanicllo V, Villamarin A, Palladino F, Schneider RJ. The adenovirus tripartite leader may climinate the requirement for cap-binding protein complex during translation initiation. $J$ Virol 1991; 62 : 2059-66.

6. Macejak DG, Sarnow P. Internal initiation of translation by the 5' leader of a cellular mRNA. Nature 1991; 353 : 90-4.

7. Jackson RJ. Initiation without an end. Nature $1991 ; 353$ : 14-5.

8. Munoz A, Alonso MA, Carrasco .. L. Synthesis of heat-shock proteins in HeLa cells : inhibition by virus infection. Virology $1984 ; 137$ : 150-9.

9. Sarnow P. Translation of glucose-regulated protein 78/immunoglobulin heavy-chain binding protein mRNA is increased in poliovirusinfected cells at a time when cap-dependent translation of cellular mRNA is inhibited. Proc Natl Acad Sa USA 1989 ; 86 : 5795-9.

10. Lindquist S. The heat shock response. Annu Rev Biochem 1986; 55 : 1151-91.

11. Panniers R, Stewart EB, Merrick WC, Henshaw EC. Mechanism of inhibition of polypeptide chain initiation in heat-shocked Ehrlich cells involves reduction of eukaryotic initiation factor 4F activity. J Biol Chem 1985 ; 260 : 9648-53.

$\mathrm{m} / \mathrm{s} n^{\circ} 1$, vol. 8 , janvier 92
La traduction des ARN messagers en protéines débute généralement par la reconnaissance de leur extrémité 5'. Chez les eucaryotes, celle-ci est modifiée par liaison covalente avec une molécule de méthyl-7-guanosine triphosphate : la coiffe ( $c a p$, en anglais). La coiffe est reconnue par le facteur d'initiation eucaryote de la traduction eIF-4F qui s'y fixe et permet l'ancrage d'un ensemble d'ARN et de protéines : la sous-unité $40 \mathrm{~S}$ du ribosome, de l'ARN de transfert pour la méthionine et des facteurs d'initiation de la traduction, eIF-2, eIF-3, eIF-4C. Puis, après association de la sous-unité $60 \mathrm{~S}$, le ribosome balaye l'ARN messager de l'extrémité 5' vers l'extrémité 3', à la recherche du premier codon, AUG, d'initiation de la traduction. Les séquences ARN encadrant ce codon sont parfois défavorables et, dans ce cas, les ribosomes continuent leur balayage jusqu'à rencontrer un AUG inséré dans un contexte favorable [1]. Une indétermination dans le choix du premier codon d'initiation peut alors être une source de diversité dans les protéines codées par un ARN donné [2]. Cependant, des protéines peuvent aussi être codées par des ARN dépourvus de coiffe. Il doit donc exister des mécanismes d'initiation de la traduction sans repérage de codon AUG à l'extrémité 5' d'un ARN : on parle alors d'initiation "interne ". Une telle situation n'était décrite que pour des ARN viraux, par exemple ceux des picornavirus et de l'adénovirus [3-5]. On pouvait supposer que les virus fournissaient la machinerie nécessaire à la traduction sans reconnaissance de l'extrémité 5' de leurs ARN. Or, un travail récent montre que des cellules de mammifères non infectées par des virus peuvent elles aussi initier la traduction d'ARN messagers indépendamment de leurs extrémités 5' $[6,7]$.

L'expérience a consisté à faire exprimer, dans des cellules de mammifère, un ARN messager comportant les séquences codant pour deux protéines test différentes. La séquence codant pour la chloramphénicol acétyl transférase précède, du côté 5', celle qui code pour la luciférase de luciole, du côté 3'. Que la cellule soit infectéc ou non, une synthèse importante de luciférase est obtenue, quelle que soit la traductibilité de la chloramphénicol acétyl transférase, pourvu qu'en 5' du codon d'initiation du gène de la luciférase, on ait placé soit une séquence 5 ' non traduite d'un gène de poliovirus, soit la séquence 5' non traduite de l'ARN codant pour la protéine BIP (heavy chain immunoglobulin binding protein). En revanche, la synthèse de luciférase est très faible si l'on placc une séquence aléatoire en 5' du premier AUG de la luciférase. Cette expérience montre : (1) la possibilité d'une initiation interne efficace de la traduction dans des cellules non infectées ; (2) que l'efficacité de cette initiation interne dépend des séquences en 5' de l'AUG d'initiation : (3) qu'une séquence d'ARN cellulaire (donc non viralc) permet une initiation interne efficace.

Le choix de la séquence 5' des ARN codant pour BIP était guidé par des considérations sur la traductibilité de BIP dans des cellules infectées par le poliovirus. En effet, lors de l'infection par le poliovirus, la synthèse des protéines cellulaires est totalement inhibée au profit de celle des protéines virales, mais la synthèse de certaines protéines diminue moins vite que celle de l'enscmble [8, 9]. Les protéines cellulaircs "résistantes" qui ont été identifiécs appartiennent toutes à la famille 
des protéines de stress : protéines de choc thermique (ou HSP) et protéines contrôlécs par la glycosylation (ou GRP, glucose-responsive protein). La protéine BIP est une GRP de $78 \mathrm{kDa}$ dont la séquence en acides aminés est particllement analoguc à celle des HSP de $70 \mathrm{kDa}$. Les séquences 5' de l'ARN codant pour BIP permettraicnt une initiation sans interaction avec l'extrémité 5' du messager.

Cette observation projettc donc un nouvel éclairage sur la traduction des ARN dans des cellules soumises à un stress. En effet, après un stress de type choc thermique, on obscrve une extinction des synthèses protéiques cellulaires suivie d'une traduction préférenticlle des ARN codant pour les protéines de choc thermique alors que les autres ARN messagers cellulaires ne sont ni dégradés ni altérés [10]. Cette traduction préférentielle s'observe aussi in vitro avec un lysat de cellules ayant subi un choc thermique. D'une part, le choc thermique, comme l'infection par lc poliovirus ou l'adénovirus, provoque l'inactivation du facteur d'initiation de la traduction eIF-4F [11, 12]. Le choc thermique inactive de nombreuses enzymes [13, 14], mais l'addition du scul facteur d'initiation de la traduction, cIF-4F purifić suffit à corriger les déficiences traductionnelles d'un lysat de cellules ayant subi un choc thermique $[15,16]$. Par conséquent, la traduction préférentielle des ARN de choc thermique s'effectue dans des conditions de nonreconnaissance de la coiffe. Comme, par ailleurs, il n'a jamais été possible d'inhiber la traduction in vitro des ARN de choc thermique par hybridation avec des séquences d'ARN complémentaires des extrémités 5' des ARN [17], il est probable que la traduction préférentielle des ARN de choc thermique résulte aussi d'un mécanisme d'initiation "interne " de la traduction comme pour les ARN du poliovirus.

Choc thermique et infection virale induisent donc des modifications similaires de la traduction dans les cellules eucaryotes, mais des mécanismes différents peuvent être impliqués. D'une part, en effet, l'inactivation par le choc thermique du facteur eIF-4F est réversible ct semble due à la déphosphorylation de la protéine p28 (ou eIF-4E), le composant de cIF-4F qui se lic à la coiffc [12, 16]. Alors que l'inactivation de eIF-4F par l'adénovirus implique aussi la déphosphorylation de la protéine p28 [18], l'inactivation par le poliovirus est irréversible et due à la protéolyse de la protéine p220, autre composant de cIF-4F, par la protéase virale $2 A^{\text {pro }}[19]$. D'autre part, les éléments de séquence responsables de la traduction préférentielle des ARN de choc thermique seraient constitués par une séquence d'une vingtaine de nucléotides présente à l'extrémité 5' de la partie 5' non traduite $[20,21]$ et peut-être aussi par des séquences situcees à l'extrémité 3' de la partie traduite [22]. Les éléments de séquence responsables de l'initiation interne de la traduction des ARN du poliovirus semblent, quant à cux, se trouver répartis sur les 500 nucléotides situés en 5' du codon AUG d'initiation $[4,23,24]$.

En conclusion, l'initiation interne de la traduction scrait particulièrement adaptéc à une synthèse massive de protéines spécifiques, lors d'une situation cellulaire critique ou pathologique

\section{Olivier Bensaude}

Groupe de biologie moléculaire du stres, École Nornale Supérieure, 46, ne d'Ulm, 75230 Paris Cedex 05, France.

\section{RÉFÉRENCES}

12. Duncan R, Milburn SC, Hershey JWB. Regulated phosphorylation and low abundance of HcLa cell initiation factor cIF-4F suggest a rolc in translational control. $J$ Biol Chem 1987 ; 262 : 380-8.

13. Pinto $M$, Morange $M$, Bensaude $O$. Denaturation of proteins during heat shock. In vivo recovery of solubility and activity of reporter enzymes. I Biol Chem 1991; 266 : 13941-6.

14. Dubois MF, Hovanessian AG, Bensaude O. Heat-shock-induced denaturation of protcins. Characterization of the insolubilization of the interferon-induced p68 kinasc. J Biol Chem 1991; 266 : 9707-11.

\section{RÉFÉRENCES}

15. Maroto FG, Sicrra JM. Translational control in heat-shocked Drosophila cmbryos. $J$ Biol Chem 1988 ; 263 : 15720-5.

16. Lamphear BJ, Pannicrs R. Cap binding protein complex that restores protein synthesis in heat-shocked Ehrlich cell lysates contains highly phosphorylated cIF-4E. J Biol Chem 1990 ; 265 : 5333-6.

17. Yost HJ, Petersen RB, Lindquist S. Posttranscriptional regulation of heat shock protcin synthesis in Drosophila. In : Morimoto H, Tissic̀res M, Gcorgopoulos S, eds. Stress Proteins in Biology and Medicine. Cold Spring Harbor : Cold Spring Harbor Laboratory Press, 1990 : 379-409.

18. Huang J. Schncider RJ. Adenovirus inhibition of cellular protein synthesis involves inactivation of cap-binding protcin. Cell 1991 ; $65: 271-80$

19. Davics MV, Pelletier J, Mccrovitch K, Sonenberg N, Kaufman RJ. The effect of poliovirus protcinase 2A pro expression on cellular metabolism. J Biol Chem 1991; 266 : 14714-20.

20. McGarry TJ, Lindquist S. The preferential translation of Drosophila hsp70 mRNA requires sequences in the untranslated leader. Cell 1985 ; 42 : 903-11.

21. Hultmark D, Klemenz R, Gchring WJ. Translational and transcriptional control clcments in the untranslated leader of the heatshock gene hsp22. Cell 1986; 44 : 429-38.

22. Denisenko ON, Yarchuk OB. Regulation of LacZ mRNA translatability in a cell-frec system at heat shock by the last four sense codons. FEBS Lett 1989 ; 247 : 251-4.

23. Pclleticr J, Kaplan G, Racanicllo VR, Sonenberg N. Cap-independent translation of poliovirus mRNA is conferred by sequence clements withing the 5' noncoding region. $\mathrm{Mol}$ Cell Biol 1988 ; 8 : 1103-12.

24. Mecrovitch K, Nicholson R, Sonenberg $\mathrm{N}$. In vitro mutational analysis of cis-acting RNA translational clements within the poliovirus type 2 5' untranslated region. J Virol 1991 ; 65 : 5895-901.

\section{TIRÉS A PART}

O. Bensaude 